\title{
Prevention of Defects of Axonal Transport and Nerve Conduction Velocity by Oral Administration of myo-Inositol or an Aldose Reductase Inhibitor in Streptozotocin-Diabetic Rats
}

\author{
J.H. Mayer and D. R. Tomlinson \\ Department of Physiology and Pharmacology, Medical School, Queen's Medical Centre, Nottingham, UK
}

\begin{abstract}
Summary. The effects of orally-administered myo-inositol have been compared with those of an aldose reductase inhibitor on acute neurological defects in experimentally diabetic rats. Three groups of streptozotocin-treated diabetic rats $(50 \mathrm{mg} / \mathrm{kg}$, IP) together with three groups of age-matched controls (saline, IP) were compared. One pair of groups (control and diabetic) were untreated for 3 weeks, another pair of groups received daily oral myo-inositol $(667 \mathrm{mg} / \mathrm{kg})$ and the third pair received an aldose reductase inhibitor (ICI 105552; $50 \mathrm{mg} \cdot \mathrm{kg}^{-1} \cdot \mathrm{day}^{-1}$, orally). The untreated diabetic group showed statistically significant deficits in accumulation, proximal to $24 \mathrm{~h}$ sciatic nerve constrictions, of choline acetyltransferase activity by comparison with untreated controls $\left(2.8 \pm 0.4\right.$ versus $5.1 \pm 0.4 \mathrm{nmol}$ acetylcholine $\cdot \mathrm{h}^{-1} \cdot$ nerve $^{-1}$; $p<0.001)$. The untreated diabetic rats also showed a fall in motor nerve conduction velocity of $6.2 \pm 0.7 \mathrm{~m} / \mathrm{s}$ which was statistically significant $(p<0.001)$. Treatment of the diabetic group with myo-inositol prevented the development of both defects of axonal transport and conduction velocity; both
\end{abstract}

measurements were similar to those of the myo-inositol treated control rats. Likewise the diabetic rats which received aldose reductase inhibitor showed prevention of both defects. Nerves from untreated diabetic rats showed marked sorbitol accumulation and a statistically significant reduction in myoinositol content by comparison with the untreated controls (sorbitol, $1.56 \pm 0.22$ versus $0.8 \pm 0.01$ and myo-inositol, $1.47 \pm 0.10$ versus $2.3 \pm 0.10 \mathrm{nmol} / \mathrm{mg} ; p<0.001)$. Treatment of the diabetic rats with myo-inositol elevated the myo-inositol levels in nerve $(3.05 \pm 0.22 \mathrm{nmol} / \mathrm{mg})$ without affecting nerve sorbitol levels. Treatment of diabetic rats with aldose reductase inhibitor also normalised nerve myo-inositol $(2.75 \pm 0.20$ $\mathrm{nmol} / \mathrm{mg})$ and reduced nerve sorbitol $(0.08 \pm 0.01 \mathrm{nmol} / \mathrm{mg})$. These findings are consistent with the suggestion that both treatments prevent the development of the two functional defects by normalising the nerve myo-inositol content.

Key words: Diabetic neuropathy, axonal transport, nerve conduction, nerve crush, myo-inositol, aldose reductase.
Investigation into the causes of diabetic neuropathy has stimulated interest in three areas of study. Firstly, there have been a number of demonstrations of disordered axonal transport in the nerves of experimentally diabetic rats [17]. Secondly, several groups of workers have shown that inhibitors of the enzyme aldose reductase prevent or ameliorate some of the acute neurological defects seen in diabetic animals $[20,25]$ and patients [4, 11]. Thirdly, there has been the discovery that administration of myo-inositol to diabetic rats reverses the reduction in nerve myo-inositol content associated with diabetes and attenuates or abolishes nerve conduction velocity defects $[8,9]$. We have sought to examine possible links between these phenomena. In a preliminary study we found that administration of an inhibitor of aldose reductase, over the first 3 weeks of streptozotocininduced diabetes in rats, prevented the development not only of nerve conduction defects but also of reduced orthograde axonal transport [20]. The present study was designed to examine the effects of normalisation of nerve myo-inositol content, by oral administration of the substance, on axonal transport and nerve conduction in acute experimental diabetes in rats. The second objective was to compare the effects of myo-inositol treatment with those of an aldose reductase inhibitor by investigating the effect of the latter on nerve myo-inositol content.

\section{Materials and Methods}

Male Wistar rats (290-310 g) were fasted overnight and made diabetic by a single injection of streptozotocin $(50 \mathrm{mg} / \mathrm{kg}$, IP) the following morning. The drug was dissolved in $0.9 \%$ saline immediately before injection. Age- and weight-matched control groups were treated iden- 
tically except that saline was injected. Three days later blood samples were taken from the streptozotocin-treated animals fasted for $2 \mathrm{~h}$ to obviate post-prandial peaks of glucose. Blood samples and glucose standards $(50 \mu \mathrm{l})$ were collected into ice-cold $0.016 \%$ uranyl acetate $(1 \mathrm{ml})$. The mixture was agitated, centrifuged at $800 \mathrm{~g}$ and the supernatant assayed for glucose spectrophotometrically by the standard glucose oxidase method (assay kit: 'GOD-PAP', Boehringer Ingelheim, London). Animals with blood glucose $<15 \mathrm{mmol} / 1$ were excluded from further study.

\section{Experimental Organisation and Treatment of Animals}

In view of previous findings [20] experiments were designed to examine the effects of 3 weeks of diabetes. Since it is possible to measure motor nerve conduction velocity (MNCV) in a recovery experiment (see below), two measurements of MNCV per rat were made, one $24 \mathrm{~h}$ before injection of streptozotocin, the other 21 days later. Earlier work [20] had shown that, in untreated diabetic rats, MNCV falls to a plateau value over this time course. Two measurements of MNCV were likewise made 21 days apart in non-diabetic control rats.

Treatment with the aldose reductase inhibitor or with myo-inositol was begun on the day of injection of streptozotocin or saline. Thus one group of diabetic rats and its control group were given a single daily dose $(50 \mathrm{mg} / \mathrm{kg}$, orally) of an aldose reductase inhibitor (ICI 105552; 1-(3,4-dichlorobenzyl)-3-methyl-1, 2-dihydro-2-oxquinol-4yl-acetic acid). A second diabetic group and its control were given daily $667 \mathrm{mg} / \mathrm{kg}$ myo-inositol orally (Sigma (London) Chemicals, Poole, Dorset, UK). Both compounds were made up in distilled water daily. These two treatments were maintained for 21 days; a third pair of diabetic and control groups were left untreated over a similar period of time.

Twenty-one days after injection of streptozotocin (or saline) the left sciatic nerve of each rat was constricted for the measurement of axonal transport. The animals were sacrificed $24 \mathrm{~h}$ later and blood samples were taken for glucose assay.

\section{Measurement of Motor Nerve Conduction Velocity}

The procedure is described in full elsewhere [16]. Rats were anaesthetized with halothane using a Boyle's Apparatus (British Oxygen, London, UK) driven with $\mathrm{O}_{2}$ and set to $5 \%$ halothane for induction and $1 \%-2 \%$ for maintenance of anaesthesia. The left sciatic nerve was stimulated first at the sciatic notch and then at the Achilles tendon. Stimulation comprised single $0.1 \mathrm{~ms}$ pulses of amplitude $1-4 \mathrm{~V}$ delivered via fine percutaneous needle electrodes. Consequent to each stimulation an electromyogram (EMG) was recorded, again using fine needle electrodes, from the second interosseus muscle via a $250 \times$ gain AC preamplifier (Scientific and Research Instruments, Croydon, Surrey, UK) on a single beam storage oscilloscope (Model 5103N, Tektronix, Beaverton, Oregon, USA). The temporal separation of the peaks of the EMGs, induced by stimulation at the two sites, was measured using dividers. The mean of six measurements was taken on each occasion. Nerve length from sciatic notch to Achilles tendon was measured at death and the distance was used to calculate MNCV in $\mathrm{m} / \mathrm{s}$.

Rectal temperature was monitored throughout anaesthesia for this procedure (2-4 min). No hypothermia was observed, all rats remaining between 37 and $38^{\circ} \mathrm{C}$.

\section{Constriction of the Sciatic Nerve}

The left sciatic nerve was ligated for $24 \mathrm{~h}$ to measure the accumulation of choline acetyltransferase activity proximal to the constriction as an index of orthograde axonal transport of the enzyme. Under halothane anaesthesia and using aseptic techniques the left sciatic nerve was exposed via a $1-\mathrm{cm}$ incision in the flank. A prolene suture $(0.7$ metric: Ethicon, Livingston, W.Lothian, Scotland) was passed around the nerve and tied tightly, level with the mid-point of the femur. The wound was closed with Michel clips (Thackray, Leeds, UK) and the animal allowed to recover. This procedure took no longer than $5 \mathrm{~min}$ from the onset of anaesthetic induction.
The rats were killed $24 \mathrm{~h}$ later by a blow on the head and bled from the throat. Both sciatic nerves were removed rapidly and placed on an ice-cold stainless steel plate. The constricted nerve was cut into $3 \mathrm{~mm}$ segments to give three segments proximal and two segments distal to the ligature. From the contralateral nerve two $3 \mathrm{~mm}$ segments were cut for comparison with the two segments immediately proximal to the ligature in the constricted nerve. These seven segments of nerve were homogenized for enzyme assay as described below. The remaining portions of the unconstricted nerve were processed for measurement of sorbitol and myo-inositol.

\section{Assay of Choline Acetyltransferase}

The method used was that described by Fonnum [5] with minor modification. Each nerve segment was homogenized in ice-cold buffer [5] in a glass-in-glass hand homogenizer. The homogenates were centrifuged at $1400 \mathrm{~g}$ for $10 \mathrm{~min}$ at $4^{\circ} \mathrm{C}$. Aliquots $(50 \mu \mathrm{l})$ of each supernatant were reacted in duplicate with $50 \mu \mathrm{l}$ of the 'working buffer' [5] containing (per $1 \mathrm{ml}$ ) $0.2 \mu \mathrm{mol}$ acetyl-coenzyme A (incorporating $0.5 \mu \mathrm{Ci}$ ${ }^{3} \mathrm{H}$-acetyl-coenzyme A), $56 \mathrm{nmol}$ choline iodide and $0.3 \mu \mathrm{mol}$ eserine sulphate. The reaction was allowed to proceed for $30 \mathrm{~min}$ at $25^{\circ} \mathrm{C}$ and was arrested by transfer of the reaction mixture to ice-cold phosphate buffer ( $5.0 \mathrm{ml}, 0.1 \mathrm{~mol} / 1$; $\mathrm{pH} 7.4)$. Radiolabelled acetylcholine was separated from unconverted acetyl-coenzyme A and measured by liquid scintillation counting [5]. Enzyme activity was calculated in units of nmol acetylcholine produced per hour per sample.

Acetyl-coenzyme A (trilithium salt) was obtained from Boehringer, Lewes, East Sussex, UK; acetyl $l^{3} \mathrm{H}$ acetyl-coenzyme A from New England Nuclear, Southampton, UK; all other chemicals were purchased from Sigma, Poole, Dorset, UK.

\section{Calculation of Accumulations}

Accumulation of enzyme activity was restricted to the two nerve segments (total length $6 \mathrm{~mm}$ ) proximal to the ligature. These segments are coded $P_{1}$ and $P_{2}$. From the sum of activities in $P_{1}$ and $P_{2}$ was subtracted the sum of the activities in the two segments taken, at the equivalent level, from the unconstricted contralateral nerve. Thus a net accumulation for each rat was obtained.

\section{Measurement of Sorbitol and myo-Inositol Content}

The bulk of the non-constricted right sciatic nerve was placed on a stainless steel plate at $4^{\circ} \mathrm{C}$, dissected free of fat and connective tissue, blotted and weighed quickly on a pre-tared micro-balance. The nerve was then boiled for $20 \mathrm{~min}$ in distilled water $(1 \mathrm{ml})$ containing $\alpha$-methyl mannoside $(30 \mu \mathrm{g} / \mathrm{ml}$; Sigma) as an internal standard. A mixture of external standards; $\alpha$-methyl mannoside, sorbitol, myo-inositol (all $30 \mu \mathrm{g} / \mathrm{ml}$; Sigma) - was similarly treated in parallel. The mixtures were cooled and deproteinized by addition of $\mathrm{ZnS} 04(0.2 \mathrm{ml}, 0.19$ $\mathrm{mol} / \mathrm{l})$ followed $10 \mathrm{~min}$ later by $\mathrm{Ba}(\mathrm{OH})_{2}(0.2 \mathrm{ml}, 0.2 \mathrm{~mol} / \mathrm{l})$. The samples were centrifuged at $800 \mathrm{~g}$ for $10 \mathrm{~min}$ and the supernatants were freeze-dried. The lyophilisates were silylated under a mixture of pyridine, hexamethyldisilazane and trimethylchlorosilane $(10: 2: 1, \mathrm{v} / \mathrm{v}$; $0.5 \mathrm{ml}$; Pierce \&Warriner, Chester, UK) [19]. After $24 \mathrm{~h}$ incubation at room temperature, distilled water $(2 \mathrm{ml})$ and cyclohexane $(0.2 \mathrm{ml}$, spectroscopic grade: British Drug Houses Chemicals, Poole, Dorset, UK) were added and the samples vortex mixed. After centrifugation at $800 \mathrm{~g}$ for $2 \mathrm{~min}$, the cyclohexane phase was aspirated off for chromatography.

Extracts were assayed in duplicate using 3\% OV3 on Chromosorb W (HP), 80/100 mesh (Pierce \&Warriner, Chester, UK) in a gas chromatograph fitted with a flame ionisation detector (Model F17, PerkinElmer, Beaconsfield, Buckinghamshire, UK). Thermal programming was used to enhance the peak height for myo-inositol. The column was held at $180^{\circ} \mathrm{C}$ for $2 \mathrm{~min}$ after sample injection and the temperature was then raised at a rate of $4^{\circ} \mathrm{C} / \mathrm{min}$ for $5 \mathrm{~min}$. Myo-inositol was eluted finally at $200^{\circ} \mathrm{C}$. Recovery of sorbital and myo-inositol was calculated from that of the internal standard, $\alpha$-methyl mannoside and was $80 \%-96 \%$. No marked within-run or day-to-day variation in recovery or sensitivity was seen. 


\section{Statistical Analyses}

All results are presented as mean \pm SEM. Examination of the significance of changes in MNCV was made using paired t-tests. Comparisons of group means for other variables were made using unpaired ttests. Linear regression analyses were performed by the method of least squares.

\section{Results}

\section{Body Weight and Blood Glucose}

The changes in body weight over the experimental period of 21 days together with the final blood glucose concentrations are shown for all groups of rats in Table 1. These data show that the streptozotocin-treated rats exhibited the classical weight loss and hyperglycaemia of this form of diabetes and that treatment of diabetic rats with either aldose reductase inhibitor or with myo-inositol had no effect on the weight loss nor upon the severity of the hyperglycaemia. Three rats died within 3 days of injection of streptozotocin. No further deaths or apparent morbidity were observed.

\section{Motor Nerve Conduction Velocity (MNCV)}

The mean MNCV for all rats at the point of entry into the study was $49.8 \pm 0.6 \mathrm{~m} / \mathrm{s}(n=54)$. The changes in $\mathrm{MNCV}$ in each group are given in Table 1. These data show that there was no change over the experimental period in the MNCV of untreated control rats whilst the untreated diabetic group showed a fall of $6.2 \pm 0.7 \mathrm{~m} / \mathrm{s}$ which was highly significant $(p<0.001)$. The two treated control groups showed small, statistically insignificant increases in MNCV over the 21 days. Treatment of diabetic rats with aldose reductase inhibitor or with myoinositol resulted in there being no significant change in MNCV over the 21 days of diabetes. Thus these treatments prevented the fall in MNCV characteristic of untreated diabetes.

\section{Axonal Transport of Choline Acetyltransferase}

The choline acetyltransferase activities measured in each nerve segment are shown in Figure 1 and the means of the calculated accumulations of activity are given in Table 1. The latter indicates that untreated diabetes caused a statistically significant reduction in choline acetyltransferase accumulation by comparison with the value obtained from the untreated control group $(p<0.001$ by unpaired t-test). The segmental distribution of choline acetyltransferase activity in the nerves of these two groups of rats (Fig. 1) shows that this reduced accumulation arose principally from a lower activity than controls in segment $P_{1}(p<0.02)$. The activity measured in the segments of unconstricted nerve was higher in untreated diabetics than in their control group. This small difference contributed to the accumulation deficit, but was not in itself significant.

Treatment with the aldose reductase inhibitor had no effect on the accumulation or distribution of choline acetyltransferase activity in the nerves of control rats. However, the aldose reductase inhibitor prevented the abberant choline acetyltransferase distribution seen in the nerves of the untreated diabetic rats. Thus the choline acetyltransferase accumulation in the nerves of the treated diabetic rats was similar to that in untreated control and significantly greater than that in untreated diabetic rats (Table $1 ; p<0.01$ ). This accumulation was a manifestation of both an increase in $\mathrm{P}_{1}$ activity and a decrease in unconstricted nerve activity.

The effects of oral administration of myo-inositol were even more marked. Treatment of the control rats produced a choline acetyltransferase accumulation which was numerically greater than that measured in the untreated controls, though the difference was not statistically significant. However, the activity in segment $\mathrm{P}_{1}$ of the constricted nerves of the myo-inositol treated control rats was significantly greater than the $P_{1}$ segment activity of the untreated control group $(p<0.001)$. The lack of significant difference between the accu-

Table 1. Changes in body weight and motor nerve conduction velocity over 21 days with final blood glucose concentrations, accumulation of choline acetyltransferase activity and nerve sorbitol and myo-inositol contents for all groups of rats

\begin{tabular}{|c|c|c|c|c|c|c|}
\hline & $\begin{array}{l}\text { Change in body } \\
\text { weight }\end{array}$ & $\begin{array}{l}\text { Blood glucose } \\
\text { concentration on } \\
\text { day } 21 \\
(\mathrm{mmol} / 1)\end{array}$ & $\begin{array}{l}\text { Change in } \mathrm{MNCV} \\
(\mathrm{m} / \mathrm{s})\end{array}$ & $\begin{array}{l}\text { Accumulation of } \\
\text { choline acetyl- } \\
\text { transferase activity } \\
\left(\text { nmol acetylcholine }^{-1} \mathrm{~h}^{-1} \text { nerve }^{-1}\right)\end{array}$ & $\begin{array}{l}\text { Sorbitol content } \\
\text { (nmol/mg nerve) }\end{array}$ & $\begin{array}{l}\text { myo-inositol } \\
\text { content } \\
\text { (nmol/mg } \\
\text { nerve) }\end{array}$ \\
\hline Untreated controls $(n=10)$ & $+13.8 \pm 1.8$ & $6.3 \pm 0.2$ & $+2.2 \pm 1.5$ & $5.1 \pm 0.4$ & $0.08 \pm 0.01$ & $2.30 \pm 0.10$ \\
\hline Untreated diabetics $(n=11)$ & $-39.5 \pm 7.1$ & $22.5 \pm 1.4$ & $-6.2 \pm 0.7^{\mathrm{a}}$ & $2.8 \pm 0.4$ & $1.56 \pm 0.22$ & $1.47 \pm 0.10$ \\
\hline $\begin{array}{l}\text { Aldose reductase inhibitor- } \\
\text { treated controls }(n=10)\end{array}$ & $+17.0 \pm 2.3$ & $4.7 \pm 0.3$ & $+2.1 \pm 1.3$ & $4.2 \pm 0.4$ & $<0.05$ & $2.51 \pm 0.12$ \\
\hline $\begin{array}{l}\text { Aldose reductase inhibitor- } \\
\text { treated diabetics }(n=7) \\
\text { myo-Inositol-treated controls }\end{array}$ & $-24.0 \pm 4.5$ & $27.5 \pm 1.2$ & $+2.6 \pm 1.7$ & $4.7 \pm 0.5$ & $0.08 \pm 0.01$ & $2.75 \pm 0.20$ \\
\hline $\begin{array}{l}(n=9) \\
\text { myo-Inositol-treated diabetics }\end{array}$ & $+24.0 \pm 2.9$ & $5.0 \pm 0.7$ & $+3.4 \pm 1.8$ & $6.2 \pm 0.7$ & $0.10 \pm 0.01$ & $2.77 \pm 0.24$ \\
\hline$(n=7)$ & $-37.8 \pm 9.8$ & $26.3 \pm 2.0$ & $+1.1 \pm 2.0$ & $6.7 \pm 0.6$ & $1.45 \pm 0.13$ & $3.05 \pm 0.22$ \\
\hline
\end{tabular}

Body weight and motor nerve conduction velocity (MNCV) values are mean \pm SEM of the differences between two measurements made the day before onset of treatment and 21 days later. ${ }^{a} p<0.001$ (paired $t$ ). By the unpaired $t$ test, the untreated diabetic rats were significantly lower in 


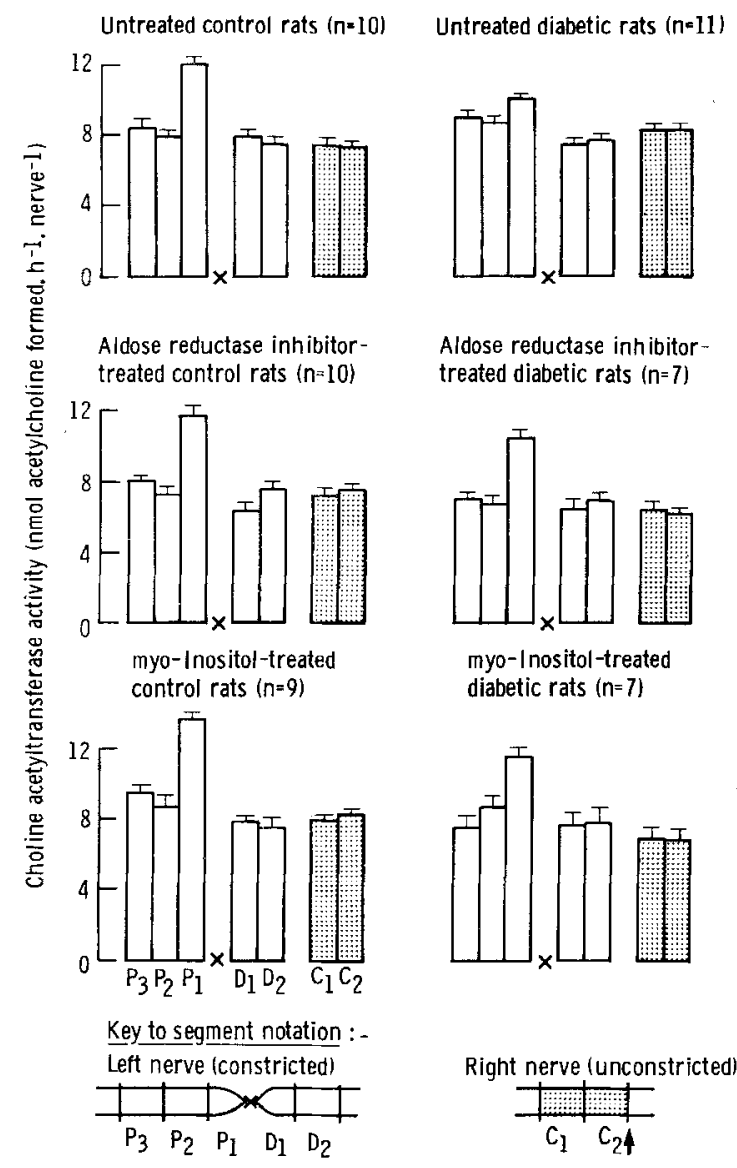

Fig. 1. The distribution of choline acetyltransferase activity between segments of constricted ( $\square$ and contralateral unconstricted ( 7 ) sciatic nerves of six groups of control and diabetic rats. Limit bars denote SEM. Nerve segments ( $3 \mathrm{~mm}$ in length) are coded with respect to the constriction (X) as indicated in the lower left-hand histogram and the key diagram. Arrow indicates the point on the unconstricted nerve level with the constriction on the contralateral trunk

mulations of activity in these two groups is attributable to the slight elevation of activity in the unconstricted nerves in the myo-inositol treated group. Treatment of diabetic rats with myo-inositol markedly elevated the accumulation of choline acetyltransferase activity $(p<0.001)$. This treatment did not produce a rise in the $\mathrm{P}_{1}$ segment activity by comparison with untreated diabetic rats, but the increase occurred together with a reduction in the activity present in unconstricted nerve. Again the latter did not attain statistical significance, but the combination of the two additive effects gave rise to a significant difference in accumulation.

\section{Nerve Content of Sorbitol and myo-Inositol}

The content of sorbitol and myo-inositol in the unconstricted sciatic nerves of all rats are given in Table 1. Comparison of untreated control with untreated diabetic rats shows that the latter accumulated a large amount of sorbitol in their nerves and this was accompanied by a deficit of myo-inositol. Both changes were highly significant $(p<0.001)$. Treatment of control rats with the aldose reductase inhibitor reduced slightly the already

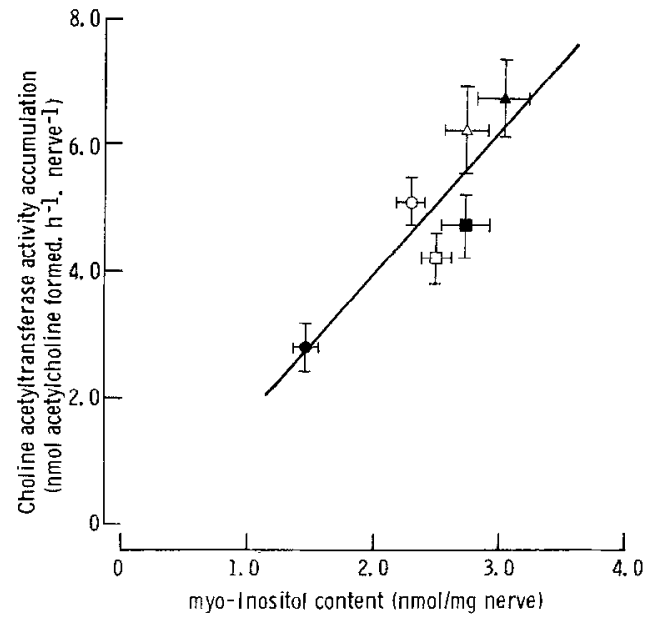

Fig. 2. Regression of choline acetyltransferase activity, accumulated proximal to constrictions in ligated left sciatic nerves, against myoinositol content of the contralateral sciatic nerve. The regression line was calculated from pairs of coordinates for individual animals. Group mean values are shown: filled symbols, diabetic, open symbols, control rats; circles, untreated ( $n=10$ controls, $n=11$ diabetics); triangles, myo-inositol treated ( $n=9$ controls, $n=7$ diabetics) and squares, rats treated with aldose reductase inhibitors $(n=10$ controls, $n=7$ diabetics). Limit bars denote SEM

very low nerve sorbitol content to a level which was just below the lower limit of the assay $(0.05 \mathrm{nmol} / \mathrm{mg}$ nerve). Aldose reductase inhibitor treatment did not affect the myo-inositol content of the nerves from the control rats, whereas in the diabetic group it completely prevented the accumulation of sorbitol and surprisingly normalized the nerve content of myo-inositol. The levels of this sugar were significantly higher than those in the untreated diabetic group $(p<0.001)$ and no different from those measured in the control rats which received the aldose reductase inhibitor.

Treatment of diabetic rats with myo-inositol prevented the reduction of nerve myo-inositol levels observed in the untreated diabetic group; the difference in nerve myo-inositol contents between treated and untreated diabetic rats being highly significant $(p<0.001)$. Indeed, treatment of the diabetics with myo-inositol raised the nerve content of this sugar to significantly higher levels than those seen in untreated control rats $(p<0.01)$. This treatment did not affect the accumulation of sorbitol, the levels being similar to those of untreated diabetic rats. Treatment of control rats with $m y o$-inositol was without significant effect on either sorbitol or myo-inositol content of sciatic nerve.

\section{Correlation of Variables}

Linear regression analyses were performed to examine possible correlations between nerve myo-inositol content and accumulation of choline acetyltransferase activity proximal to the constriction and between nerve myo-inositol content and the change over 21 days in motor nerve conduction velocity. These analyses were performed on pairs of data from each animal. There was no significant correlation between nerve myo-inosi- 
tol and conduction velocity; but the correlation between myo-inositol content and accumulation of choline acetyltransferase activity was highly significant (Fig. 2).

\section{Discussion}

This investigation has studied the effects of treatment of diabetic rats, either with an inhibitor of aldose reductase or with myo-inositol, on two functional neurological defects characteristic of acute diabetes, namely reduced motor nerve conduction velocity and impaired orthograde axonal transport. The existence of reduced motor nerve conduction velocity as an early complication of diabetes is well established both in man and in several species of animals with various forms of experimental diabetes. The particular axonal transport defect studied here has received much less attention but is also well established. Impaired orthograde axonal transport of choline acetyltransferase activity was first described some time ago [15] when a reduction of about $40 \%$ in accumulation proximal to a sciatic nerve constriction was seen after 3-4 weeks of streptozotocin-induced diabetes. In a previous study, we found a $39 \%$ reduction in choline acetyltransferase activity accumulation after 3 weeks of diabetes [20] which compares well with the reduction of $45 \%$ of the present investigation.

The wasting of the muscles of the flank in uncontrolled diabetes in rats reduces thermal insulation of the sciatic nerve. Selection of anaesthetic and control of ambient temperature are therefore important to preclude slowing of conduction due to nerve cooling. We have used local heating whilst monitoring nerve temperature via a needle thermistor to prevent cooling during barbiturate anaesthesia [20]. In pilot studies with halothane, normothermia was much more readily accomplished due to brisk induction and very short duration of anaesthesia. In the present study neither nerve nor rectal hypothermia were encountered. It is possible that nerve hypothermia could reduce axonal transport during the 24-h accumulation period when ambient temperature was not controlled. The only argument against this possibility is the finding that both the aldose reductase inhibitor and myo-inositol treatments gave normal axonal transport in diabetic rats with profound weight loss and muscle wasting.

The prevention of deficits of choline acetyltransferase accumulation and nerve conduction velocity by treatment of diabetic rats with ICI 105552 is a confirmation of our earlier findings [20]. Inhibition of aldose reductase with Alrestatin has been found to ameliorate the motor nerve conduction velocity defect in galactosefed rats [6] and to attenuate some nerve conduction defects in diabetic patients [4]. Sorbinil, another inhibitor of aldose reductase, which is structurally unrelated to ICI 105552, also ameliorates the motor nerve conduction velocity deficit in diabetic rats [25] and diabetic patients [11]. It appears, therefore, that inhibition of aldose reductase has unequivocal beneficial effects on nerve conduction defects attributable to acute diabetes. In similar experiments, we have found that treatment of diabetic rats with Sorbinil not only prevents the development of deficient choline acetyltransferase activity accumulation, but also reverses the defect once it has been established at three weeks of untreated diabetes [12].

A deficiency of myo-inositol in the nerves of animals with acute experimental diabetes has been reported [3, $8,13,21,23]$ and oral administration of myo-inositol has been shown to reverse the deficiency in nerve content and attenuate nerve conduction velocity defects $[8,9]$. In the present context, this finding acquires added interest because of the effect of the aldose reductase inhibitor on nerve myo-inositol content. The two treated diabetic groups show the common feature that deficiency of nerve myo-inositol content was prevented by both treatments.

The implication of nerve myo-inositol content as an influence on axonal transport of choline acetyltransferase activity is supported by the highly significant correlation of the two variables (Fig. 2).

We consider that the beneficial effects of aldose reductase inhibition on acute neuronal dysfunction in diabetes may not be related directly to prevention of the accumulation of sorbitol or fructose. Instead, we suggest that the effects may be mediated, at least in substantial part, by correction of the nerve myo-inositol deficit. However, this does not preclude the possibility that hydrodynamic or biochemical consequences of sorbitol and fructose accumulation play some part in reducing the capacity of the nerve to accumulate and maintain a normal content of myo-inositol. It is otherwise difficult to understand how inhibitors of aldose reductase could act to normalize the nerve myo-inositol content. It is generally accepted that the reduced nerve content in diabetes arises as a result of competitive inhibition of uptake of myo-inositol by high levels of extracellular glucose. This phenomenon is widely reported for lens, kidney and gut $[1,2,10,21]$ and has more recently been shown to occur in peripheral nerve in vitro [7]. Thus, elevation of plasma myo-inositol, following oral administration of the substance, would be expected to reverse competitively the effects of hyperglycaemia on myo-inositol uptake by nerve. This hypothesis may be naive. Others have observed that some two weeks of treatment of diabetic rats with myo-inositol must elapse before a significant improvement in $\mathrm{MNCV}$ is seen [9]. Studies in our laboratory, involving treatment of diabetic rats with Sorbinil, in which we found that normalization of nerve myo-inositol content precedes by at least 1 week any improvement in either MNCV or axonal transport (unpublished work) support this view. This observation is not surprising, however, since the normalization of free myo-inositol in nerve is unlikely to have a direct effect on functional phenomena such as impulse conduction or axonal transport. The time lag may indicate secondary processes of biochemical repair such as incorporation of myo-inositol into phospholipids and return to normal of the activity of CDP-digly- 
ceride: inositol transferase [3]. The influence of aldose reductase inhibition on the latter processes would be a profitable area of study.

The majoritiy of work concerned with nerve myo-inositol and aldose reductase inhibitors has focussed upon nerve conduction velocity as a functional manifestation of diabetes-induced neurological disorder. Thus interest has been restricted to acute neuropathies. The present implication of myo-inositol and aldose reductase in the development of defective axonal transport, may relate also to chronic neuropathy. The delivery of macromolecules to the periphery of the neurone by axonal transport is vital to the maintenance of the axon and its terminals [14]. Disorder of this process could contribute to degenerative neuronal dysfunction in diabetes, in which case, study of the effects of aldose reductase inhibitors and the processes whereby the nerve utilises myo-inositol and its phospholipid derivatives may be of benefit in understanding the aetiology and potential management of a variety of diabetic neuropathies. As yet there is little understanding of the factors which influence or regulate, under physiological conditions, conduction velocity and axonal transport. We have a similar limited view of the reasons underlying the importance of the high levels of myo-inositol in normal nerve. However, a recent report [18] suggests that a high level of myo-inositol may be necessary to prevent a restriction on phosphatidylinositol synthesis at sites of rapid turnover, where this process may be important for metabolic regulation of a variety of neurophysiological processes. The present findings vindicate the arguments of others [24] who predicted that aldose reductase inhibition might exert beneficial effects in nerve by normalizing myo-inositol content.

Acknowledgements. This work was supported by the British Diabetic Association; we also thank them for maintenance of JHM. We thank ICI Pharmaceuticals Division for gifts of drugs, Dr. D.C. N. Earl, for his interest and support, and Mr. D. Merlees for advice on chromatography. We are grateful to Mr. I. Topham and Miss E. Spencer for technical assistance and last, but not least, to Dr. K. R. W. Gillon for stimulating our interest in myo-inositol.

\section{References}

1. Brockhuyse RM (1968) Changes in myo-inositol permeability in the lens due to caractous condition. Biochim Biophys Acta 163: 269-272

2. Caspary WF, Crane RK (1970) Active transport of myo-inositol and its relation to the sugar transport system in hamster small intestine. Biochim Biophys Acta 203: 308-316

3. Clements RS Jr, Stockard CR (1980) Abnormal sciatic nerve myoinositol metabolism in the streptozotocin-diabetic rat. Diabetes 29: $227-235$

4. Fagius J, Jameson S (1981) Effects of aldose reductase inhibitor treatment in diabetic polyneuropathy - a clinical and neurophysiological study. J Neurol Neurosurg Psychiatr 44: 991-1001

5. Fonnum $F$ (1973) A rapid radiochemical method for the determination of choline acetyltransferase. J Neurochem 24: 407-409

6. Gabbay KH (1973) Role of sorbitol pathway in neuropathy. In: Camerini-Davalos RA, Cole HS (eds) Vascular and neurological changes in early diabetes. Academic Press, New York London, p 417-424
7. Gillon KRW, Hawthorne JN (1983) Transport of myo-inositol into endoneurial preparations of sciatic nerve from normal and streptozotocin-diabetic rats. Biochem J 210: 775-781

8. Greene DA, de Jesus PV Jr, Winegrad AI (1975) Effects of insulin and dietary myo-inositol on impaired peripheral motor nerve conduction velocity in acute streptozotocin-diabetes. J Clin Invest 55: $1326-1336$

9. Greene DA, Lewis RA, Lattimer SA, Brown MJ (1982) Selective effects of myo-inositol administration on sciatic and tibial motor nerve conduction parameters in the streptozotocin diabetic rat. Diabetes 31: $573-578$

10. Hauser G (1965) Energy- and sodium-dependent uptake of inositol by kidney cortex slices. Biochem Biophys Res Commun 19: 696-701

11. Judzewitsch RG, Jaspan JB, Polonsky KS, Weinberg CR, Halter JB, Halar E, Pfeifer MA, Vukadinovic C, Bernstein L, Schneider M, Liang K-Y, Gabbay KH, Rubenstein AH, Porte D Jr (1983) Aldose reductase inhibition improves nerve conduction velocity in diabetic patients. New Engl J Med 308: 119-125

12. Mayer JH, Moriarty RH, Tomlinson DR (1983) Prevention and amelioration of neurological defects in acute experimental diabetes by Sorbinil, an aldose reductase inhibitor. Br J Pharmacol (in press)

13. Palmano KP, Whiting PH, Hawthorne JN (1977) Free and lipid myo-inositol in tissues from rats with acute and less severe streptozotocin-induced diabetes. Biochem J 167: 229-235

14. Perísíc M, Cuénod M (1972) Synaptic transmission depressed by colchicine blockade of axoplasmic flow. Science 175: 1140-1142

15. Schmidt RE, Matschinskly FM, Godfrey DA, Williams AD, McDougal DB (1975) Fast and slow axoplasmic flow in sciatic nerve of diabetic rats. Diabetes 24: 1081-1085

16. Sharma AK, Thomas PK (1974) Peripheral nerve structure and function in experimental diabetes. J Neurol Sci 23:1-15

17. Sidenius $P$ (1982) The axonopathy of diabetic neuropathy. Diabetes $31: 356-363$

18. Simmons DA, Winegrad AI, Martin DB (1982) Significance of tissue $m y o$-inositol concentrations in metabolic regulation in nerve. Science 217: 848-851

19. Sweeley CC, Bentley R, Makita M, Wells WW (1963) Gas-liquid chromatography of trimethylsilyl derivatives of sugars and related substances. J Am Chem Soc 85: 2497-2507

20. Tomlinson DR, Holmes PR, Mayer JH (1982) Reversal, by treatment with an aldose reductase inhibitor, of impaired axonal transport and motor nerve conduction velocity in experimental diabetes. Neurosci Lett 31: 189-193

21. Varma SD, Chakraponi B, Reddy VN (1970) Intraocular transport of myo-inositol. II. Accumulation in the rabbit lens in vitro. Invest Ophthalmol 9: 794-800

22. Ward JD, Baker RWR, Davis BH (1972) Effect of blood sugar control on the accumulation of sorbitol and fructose in nervous tissue. Diabetes 21: 1173-1178

23. Winegrad AI, Greene DA (1977) Diabetic polyneuropathy: the importance of insulin deficiency, hyperglycaemia and alterations in myo-inositol metabolism in its pathogenesis. New Engl J Med 295: 1416-1421

24. Winegrad AI, Simmons DA, Martin DB (1983) Has one diabetic complication been explained? New Engl J Med 308: 152-154

25. Yue DK, Hanwell MA, Satchell PM, Turtle JR (1982) The effect of aldose reductase inhibition on motor nerve conduction velocity in diabetic rats. Diabetes 31:789-794

Received: 10 January 1983

and in revised form: 9 August 1983

Dr. D.R.Tomlinson

Department of Physiology and Pharmacology

Medical School

Queen's Medical Centre

Clifton Boulevard

Nottingham NG7 2UH

UK 